\title{
Determination of Selected Nitropolycyclic Aromatic Hydrocarbons in Water Samples
}

\author{
Yvonne Chondo, ${ }^{*, a}$ Ying Li,${ }^{d}$ Fumiya Makino, ${ }^{b}$ Ning Tang, ${ }^{a, c}$ Akira Toriba ${ }^{a, c}$ \\ Takayuki Kameda, ${ }^{e}$ and Kazuichi Hayakawa ${ }^{a, c}$ \\ ${ }^{a}$ Graduate School of Medical Sciences, Division of Pharmaceutical Sciences, Kanazawa University; ${ }^{b}$ College of \\ Medical, Pharmaceutical and Health Sciences, School of Pharmacy, Kanazawa University; ' Institute of Medical, \\ Pharmaceutical and Health Sciences, Kanazawa University; Kakuma-machi, Kanazawa, Ishikawa 920-1192, Japan: \\ ${ }^{d}$ Department of Chemical and Chemical Engineering, Henan Institute of Science and Technology; Xinxiang, Henan \\ 453003, China: and ${ }^{e}$ Department of Socio-Environmental Energy Science, Graduate School of Energy Science, Kyoto \\ University; Yoshida-honmachi, Sakyo-ku, Kyoto 606-8501, Japan.
}

Received July 11, 2013; accepted September 16, 2013

A new method for the analysis of selected nitropolycyclic aromatic hydrocarbons (NPAHs) at ultra-trace levels in water samples is proposed. Particulate NPAHs were collected on a GC glass fiber filter. Soluble NPAHs were collected on a C18 Empore disk. After simple clean-up and concentration of NPAHs in both phases, the NPAHs were analyzed using HPLC equipped with clean-up, reducer, concentration and chemiluminescence detection units. The proposed method showed good linear calibration curves with correlation coefficients $\left(r^{2}\right)$ ranging from 0.9954 to 0.9998 . The limits of detection ranged from 0.013 to $0.15 \mathrm{nmol} / \mathrm{L}$ (soluble NPAHs) and from 0.01 to $0.13 \mathrm{nmol} / \mathrm{L}$ (particulate NPAHs) for 5 NPAHs [(9-nitroanthracene, 1-nitropyrene, 6-nitrochrysene (6-NC), 7-nitrobenz $[a]$ anthracene and 6-nitrobenzo[ $a]$ pyrene] having 3 to 5 rings analyzed, when $1.5 \mathrm{~L}$ of water sample was used. The repeatability for soluble NPAHs ranged between 4.2 and $6.8 \%$ $(n=5)$, while for particulate NPAHs, it varied between 2.2 and $2.8 \%(n=5)$. The proposed method successfully determined the above NPAHs expect 6-NC in river water samples, suggesting that this method is suitable for the ultra-trace analysis of NPAHs in water samples.

Key words nitropolycyclic aromatic hydrocarbon; HPLC; water analysis; river water

Polycyclic aromatic hydrocarbons (PAHs) and their nitrated derivatives (NPAHs) are formed through incomplete combustion of fossil fuels like coal and oil and through pyrolysis of organic materials. These pollutants are emitted from cars, factories, oil and coal stoves and cigarettes etc. mainly as gases and solid particles. ${ }^{1)}$ PAHs are also contained in natural oil. $^{2)}$ Additionally, several NPAHs such as 2-nitrofluoranthene (NFR) and 2-nitropyrene are formed in a secondary process through the gas phase reaction of PAHs with hydroxyl $(\mathrm{OH})$ and dinitrogen pentoxide $\left(\mathrm{N}_{2} \mathrm{O}_{5}\right)$ radicals, and nitrogen oxides $\left(\mathrm{NO}_{x}\right)$ which are found abundantly in the polluted atmosphere. $^{3,4)}$

PAHs and NPAHs are widespread environmental contaminants in the atmosphere, soil and water systems ${ }^{5)}$ and are known to show carcinogenicity and/or mutagenicity. International Agency of Research of Cancer (IARC) has placed 1-nitropyrene (1-NP) and 6-nitrochrysene (6-NC) in Group 2A (probably carcinogenic to humans) and 1,6-, 1,8-dinitropyrenes (DNPs), 2-nitrofluorene and several other NPAHs in Group B (possibly carcinogenic to humans). ${ }^{6}$ Some NPAHs are more mutagenic than their parent PAHs in the Salmonella typhimurium bacterial assay and several have shown carcinogenic potential in animals as well. ${ }^{7)}$

Although NPAHs are highly mutagenic, the concentrations of major NPAHs like 1-NP are at less than $\mathrm{fmol} / \mathrm{m}^{3}$ levels, which are much lower than those of PAHs (1 to $\left.100 \mathrm{pmol} / \mathrm{m}^{3}\right)$ in urban air. ${ }^{8)}$ Consequently, NPAHs also exist at much lower concentrations in environmental water compared to those in the atmosphere or soil. ${ }^{5)}$ There are several reports concerning the analysis of NPAHs in the atmosphere ${ }^{9-11)}$ and soil. ${ }^{12,13)}$ Re- ports concerning the analysis of PAHs in environmental water samples like sea water, are also abundant. ${ }^{14,15)}$ However, there is very little data concerning NPAHs in water samples. The available reports used HPLC coupled with fluorescence (FL) or chemiluminescence (CL) detection. ${ }^{16)}$ In the case of NPAHs in environmental water samples, a good pretreatment/preconcentration method of the water samples is necessary in order to get good sensitivity. Solid phase microextraction coupled to GC-MS has been previously used to detect trace level NPAHs in environmental water. ${ }^{17}$ ) Other reports have used electroanalytical methods like differential pulse polarography (DPP), differential pulse voltammetry (DPV) and adsorptive stripping voltammetry (AdSV) coupled with liquid-liquid extraction or solid-phase extraction in order to analyze trace NPAHs found in water samples. ${ }^{18)}$

Because of the scarcity of reports about the pretreatment/ preconcentration methods for NPAHs in water samples, this report proposes a C18 disk concentration method (solid phase extraction) for extraction of soluble NPAHs from water samples, coupled with a liquid-liquid extraction method for extraction of NPAHs found in particulates collected from water samples by a glass filter, and then uses HPLC coupled with CL detection to analyze the NPAHs in both phases. This enables the calculation of total NPAHs (both in the soluble and particulate phase). C18 disk was chosen because it could collect trace levels of PAHs in large volume water samples with high recoveries and low limits of detection. ${ }^{19)}$ The performance of the proposed method was validated and then the method was used to determine selected NPAHs in environmental water samples. 


\section{Experimental}

Chemicals Five NPAHs, 9-nitroanthracene (9-NA), 1-NP, 6-NC, 7-nitrobenz $[a]$ anthracene $(7-\mathrm{NBaA})$ and 6-nitrobenzo[a]pyrene (6-NBaP) were purchased from Accustandard, Inc. (New Haven, CT, U.S.A.). These NPAHs were chosen to represent different number of rings (3-5 rings) which are directly emitted from combustion of fossil fuels. The main physical and chemical properties of these NPAHs are shown in Table 1. 2-Fluoro-7-nitrofluorene (FNF) was purchased from Aldrich Chemical Company, Inc. (Milwaukee, WI, U.S.A.) as an internal standard for NPAHs analysis. All the analytes were dissolved in acetonitrile obtained from Kanto Chemical Co., Inc. (Tokyo, Japan) to make different concentrations of NPAHs.

Chemicals used for the extraction and clean-up of NPAHs found in the particulate phase were as follows: benzene and ethanol (for pesticide residue and polychlorinated biphenyl (PCB) analysis) used for extraction were obtained from Wako Pure Chemical Industries, Ltd. (Kyoto, Japan) and their mixture was prepared in the ratio of $3: 1(\mathrm{v} / \mathrm{v})$. Sodium hydroxide and sulphuric acid used for washing were also obtained from Wako Pure Chemical Industries, Ltd. and were prepared every $2 \mathrm{~d}$ by dissolving in deionised water to make $5 \%(\mathrm{v} / \mathrm{v})$ and 20\% (v/v) solutions, respectively. Deionised water used for experiments was prepared on a water purification system obtained from Sartorius Stedim Biotech GmbH (Goettingen, Germany). All solvents (acetonitrile, dichloromethane, ethanol, benzene and hexane) and other chemicals used for HPLC were HPLC or analytical grade.

River Water The river water samples used for NPAH recovery and repeatability studies were collected from Asano River, Kanazawa city, Japan. The surface water, $1.5 \mathrm{~L}$ was collected by immersing pre-cleaned borosilicate amber glass bottles into the river. After sampling, to avoid adsorption of NPAHs upon glassware and to reduce influence of microorganism in river water sample, $5 \%(\mathrm{v} / \mathrm{v}), 75 \mathrm{~mL}$ of methanol was added to $1.5 \mathrm{~L}$ of water and the solution was mixed thoroughly. River water samples were stored at $4^{\circ} \mathrm{C}$ until analysis.
Sample Preparation River water sample was filtered through a $0.45 \mu \mathrm{m}$ micropore membrane (GC-50, diameter $47 \mathrm{~mm}$ Advantec, Tokyo, Japan) to separate the particulate and soluble phases of NPAHs. The GC-50 disk was first preconditioned using $15 \mathrm{~mL}$ of ethanol and then $15 \mathrm{~mL}$ of distilled water, before the sample was passed through it. After the sample had all been passed through, the GC filter was dried by suction for $20 \mathrm{~min}$. One hundred $\mu \mathrm{L}$ of FNF $(10 \mu \mathrm{mol} / \mathrm{L}$ dissolved in acetonitrile) was then added to the filtrate and the solution was filtered through C18 3M Empore disk (Bioanalytical Technologies, St. Paul, MN, U.S.A.) preconditioned using $40 \mathrm{~mL}$ of methanol, $20 \mathrm{~mL}$ of dichloromethane and $20 \mathrm{~mL}$ of water, at a flow rate of $300 \mathrm{~mL} / \mathrm{min}$ to collect soluble NPAHs.

The disk was suctioned for $20 \mathrm{~min}$ to completely remove all the water and then dried overnight in a desiccator wrapped in aluminium foil. The GC filter was cut into small $5 \mathrm{~mm}$ square pieces and put in a conical flask. After the addition of $100 \mu \mathrm{L}$ of FNF internal standard, $20 \mathrm{~mL}$ of benzene and ethanol were added in the ratio of $3: 1(\mathrm{v} / \mathrm{v})$. The mixture was supersonicated for $15 \mathrm{~min}$ and transferred into a separating funnel through filter paper, taking care not to transfer the cut GC filter pieces as well. The GC filter pieces in the conical flask were then supersonicated again using $20 \mathrm{~mL}$ of fresh benzene-ethanol $(3: 1, \mathrm{v} / \mathrm{v})$, for $10 \mathrm{~min}$ and once more filtered via a filter paper into the separating funnel. The solutions containing particulate NPAHs were mixed in the separating funnel and then washed successively using $40 \mathrm{~mL}$ of $5 \%$ sodium hydroxide, $40 \mathrm{~mL}$ of $20 \%$ sulfuric acid and then $40 \mathrm{~mL}$ of distilled water, twice. Afterwards, $100 \mu \mathrm{L}$ of dimethyl sulfoxide (DMSO) was added, and the mixture was evaporated. Finally, $900 \mu \mathrm{L}$ of ethanol was added into the residue to make $1 \mathrm{~mL}$ of aliquot.

The C18 disk was collected in a conical flask and then $20 \mathrm{~mL}$ of dichloromethane was added. The disk was supersonicated for $10 \mathrm{~min}$ and the dichloromethane solution was transferred into a round-bottomed flask through a filter paper. The disk was supersonicated again with $20 \mathrm{~mL}$ of dichloromethane for another $10 \mathrm{~min}$. The solutions containing soluble

Table 1. Main Physical and Chemical Properties of Five NPAHs Analyzed

\begin{tabular}{|c|c|c|c|c|}
\hline Analyte (abbreviation) & Structure & Molecular formula & Molecular weight & CAS number \\
\hline 9-Nitroanthracene (9-NA) & & $\mathrm{C}_{14} \mathrm{H}_{9} \mathrm{NO}_{2}$ & 223.231 & $602-60-8$ \\
\hline 1-Nitropyrene (1-NP) & & $\mathrm{C}_{16} \mathrm{H}_{9} \mathrm{NO}_{2}$ & 247.248 & $5522-43-0$ \\
\hline 6-Nitrochrysene (6-NC) & $N$ & $\mathrm{C}_{18} \mathrm{H}_{11} \mathrm{NO}_{2}$ & 273.28 & $7496-02-8$ \\
\hline $\begin{array}{l}\text { 7-Nitrobenz }[a] \text { anthracene } \\
\quad(7-\mathrm{NBaA})\end{array}$ & $\mathrm{NO}_{2}$ & $\mathrm{C}_{18} \mathrm{H}_{11} \mathrm{NO}_{2}$ & 273.28 & $20268-51-3$ \\
\hline $\begin{array}{l}\text { 6-Nitrobenzo }[a] \text { pyrene } \\
\quad(6-\mathrm{NBaP})\end{array}$ & $D_{2}$ & $\mathrm{C}_{20} \mathrm{H}_{11} \mathrm{NO}_{2}$ & 297.32 & $63041-90-7$ \\
\hline
\end{tabular}




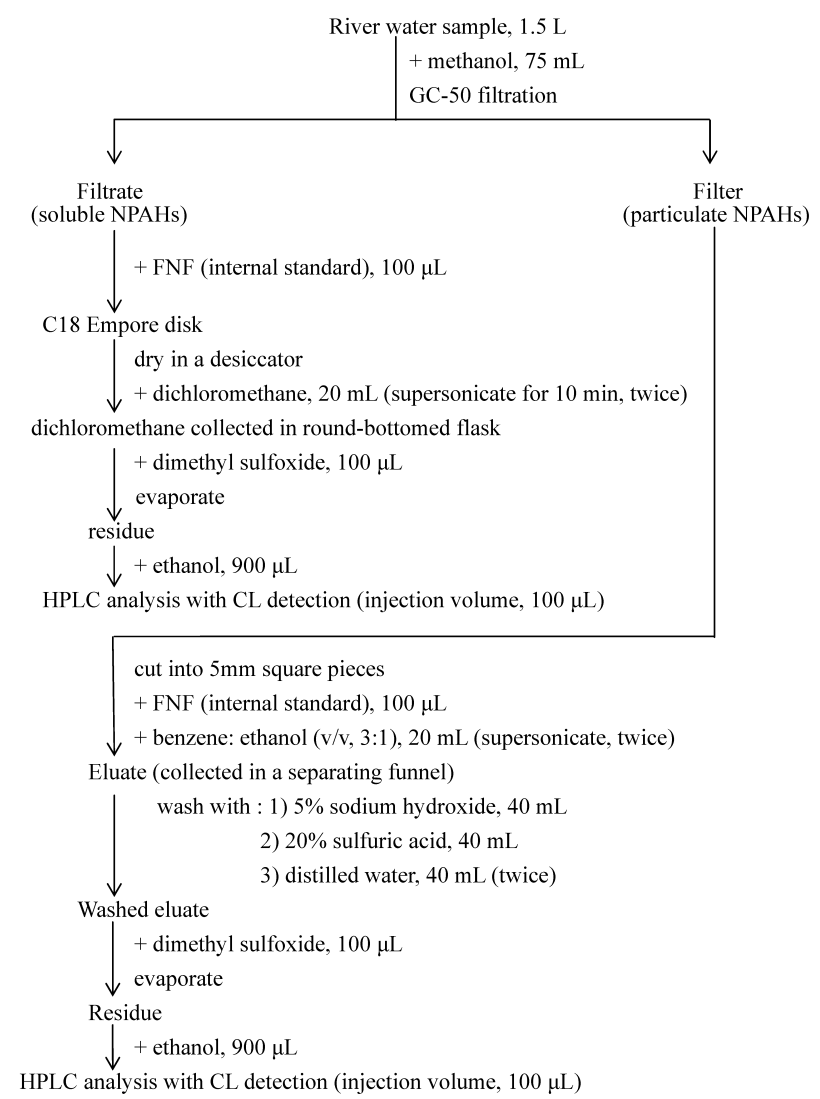

Chart 1. Flow Chart of Extraction Method and Clean-Up for Soluble and Particulate Phase NPAHs

NPAHs were again collected in the round-bottomed flask. After $100 \mu \mathrm{L}$ of DMSO was added, the mixture was evaporated away. Finally, $900 \mu \mathrm{L}$ of ethanol was added into the residue to make $1 \mathrm{~mL}$ of aliquot. Both sample solutions of soluble and particulate NPAHs were analyzed by HPLC with CL detection.The proposed pretreatment procedures for NPAHs in both the soluble and particulate phases are summarized in Chart 1.

Calibration Curves, Limit of Detection (LOD), Limit of Quantification (LOQ) and Recovery Eight concentration levels of calibration standards $(0.02$ to $4 \mathrm{nmol} / \mathrm{L}$ for each NPAH) were prepared. Three sets of calibration curves were generated on three separate days during method validation. The LOD was determined by spiking 6 to 8 samples of river water with a known concentration of NPAHs, and extracting the samples using the extraction method and analysis system described in this report. The LOD was then calculated as 3 times the standard deviation obtained from spiked tests, and the LOQ was calculated as 10 times the standard deviation obtained from spiked tests. To evaluate analyte recovery from the sample, river water samples were spiked with a known amount of analyte. The percentage recovery is calculated by comparing the difference of the spiked and non-spiked samples.

HPLC Analysis We reported a HPLC/chemiluminescence detection system for the highly sensitive determination of NPAHs. ${ }^{20-22)}$ In this study, 5 NPAHs were determined using the same HPLC system with several modifications. The proposed HPLC system (Fig. 1), consisted of seven HPLC columns: a guard column 1 (Spheri-5 RP-18, 4.6 i.d. $\times 30 \mathrm{~mm}$, $20^{\circ} \mathrm{C}$, PerkinElmer, Inc.) a guard column 2 (Shodex Asa- hipak ODP-50G 6A, 4.6 i.d. $\times 50 \mathrm{~mm}, 20^{\circ} \mathrm{C}$, Showa Denko), a clean-up column (Cosmosil 5C18-MS-II, 4.6 i.d. $\times 150 \mathrm{~mm}$, $20^{\circ} \mathrm{C}$, Nacalai Tesque), a reducer column packed with $\mathrm{Pt} / \mathrm{Rh}$, (4.0 i.d. $\times 10 \mathrm{~mm}, 80^{\circ} \mathrm{C}$, Shimadzu), a concentrator column (Spheri-5 RP-18, 4.6 i.d. $\times 30 \mathrm{~mm}, 20^{\circ} \mathrm{C}$, PerkinElmer, Inc.) and two separator columns (Cosmosil 5C18-MS, 4.6 i.d. $\times 150 \mathrm{~mm}$, $20^{\circ} \mathrm{C}$ and Cosmosil 5C18-MS, 4.6 i.d. $\times 250 \mathrm{~mm}, 20^{\circ} \mathrm{C}$, both from Nacalai Tesque). It also consisted of mobile phase pumps (LC-20AD, Shimadzu, Kyoto, Japan), a chemiluminescence reagent solution pump (LC-20AD), a chemiluminescence detector (CLD-10A, Shimadzu), a system controller (CBM-20A, Shimadzu), a chromatopac integrator (C-R4A, Shimadzu), a degasser (DGU-14A, Shimadzu), an auto sample injector (SIL20AC, Shimadzu), and two column ovens (both CTO-20AC, Shimadzu), one for separation $\left(20^{\circ} \mathrm{C}\right)$ and one for reduction $\left(80^{\circ} \mathrm{C}\right)$.

The injection volume of the sample solutions was $100 \mu \mathrm{L}$, which was five times larger than our previous system. ${ }^{22)}$ The mobile phases used for concentration were ethanol-acetic acid $(\mathrm{pH} 5.5)$ buffer $(3: 1 \mathrm{v} / \mathrm{v})$, at a flow rate of $0.3 \mathrm{~mL} / \mathrm{min}$ and $30 \mathrm{~mm}$ ascorbic acid at a flow rate of $1.8 \mathrm{~mL} / \mathrm{min}$. For separation purposes, imidazole- $\mathrm{HClO}_{4}$ buffer $(\mathrm{pH}$ 7.6) at a flow rate of $0.5 \mathrm{~mL} / \mathrm{min}$ and acetonitrile at a flow rate of $0.5 \mathrm{~mL} / \mathrm{min}$ were used. The chemiluminescence reagent solutions used were bis(2,4,6-trichlorophenyl)oxalate (TCPO) and hydrogen peroxide dissolved in $1 \mathrm{~L}$ of acetonitrile to make $0.04 \mathrm{~mm}$ and $30 \mathrm{~mm}$ concentrations, respectively.

After the sample solution was injected into the system, the NPAHs were separated from coexisting substances on the clean-up column. The NPAHs were introduced into the reducer column and reduced to their corresponding amino derivatives (APAHs). The band of APAHs was hart-cutted and concentrated on the concentration column. Then the APAHs were eluted with imidazole- $\mathrm{HClO}_{4}$ buffer and acetonitrile, and separated on the separator columns. The APAHs, separately eluted from the columns, were detected chemilumigenically.

For the five NPAHs selected in this study, it is possible to modify the time program so that retention times are shorter. However, the time program that was used in this experiment can be applicable not only for the five NPAHs selected for this study, but also for the simultaneous separation and analysis of 21 NPAHs, making it suitable over a wide range. For this reason, it was chosen in this experiment.

\section{Results and Discussion}

GC-50 Filter and C18 Disk In our previous report, NPAHs existed in the particulate and soluble phases in rain water samples. ${ }^{23)}$ In the proposed method, the GC-50 filter (pore size $0.45 \mu \mathrm{m}$ ) was used to separate NPAHs in the two phases. Considering the concentrations of NPAHs in the precipitates were very low, ${ }^{23}$ the concentrations of NPAHs in river and sea water samples might be much lower than those in precipitates. We already developed an online concentration/ determination HPLC system for the analysis of trace level PAHs. ${ }^{14)}$ Although this online concentration system was useful for water samples less than $1 \mathrm{~L}$, it required a lot of time (more than a few hours) when several liters of water samples were used. To concentrate ultra-trace levels of NPAHs in much larger volumes of water samples quickly, a C18 disk was used. This disk collected NPAHs at nmol/L levels quantitatively from water samples at a flow rate of $300 \mathrm{~mL} / \mathrm{min}$ (Tables 2, 3). 


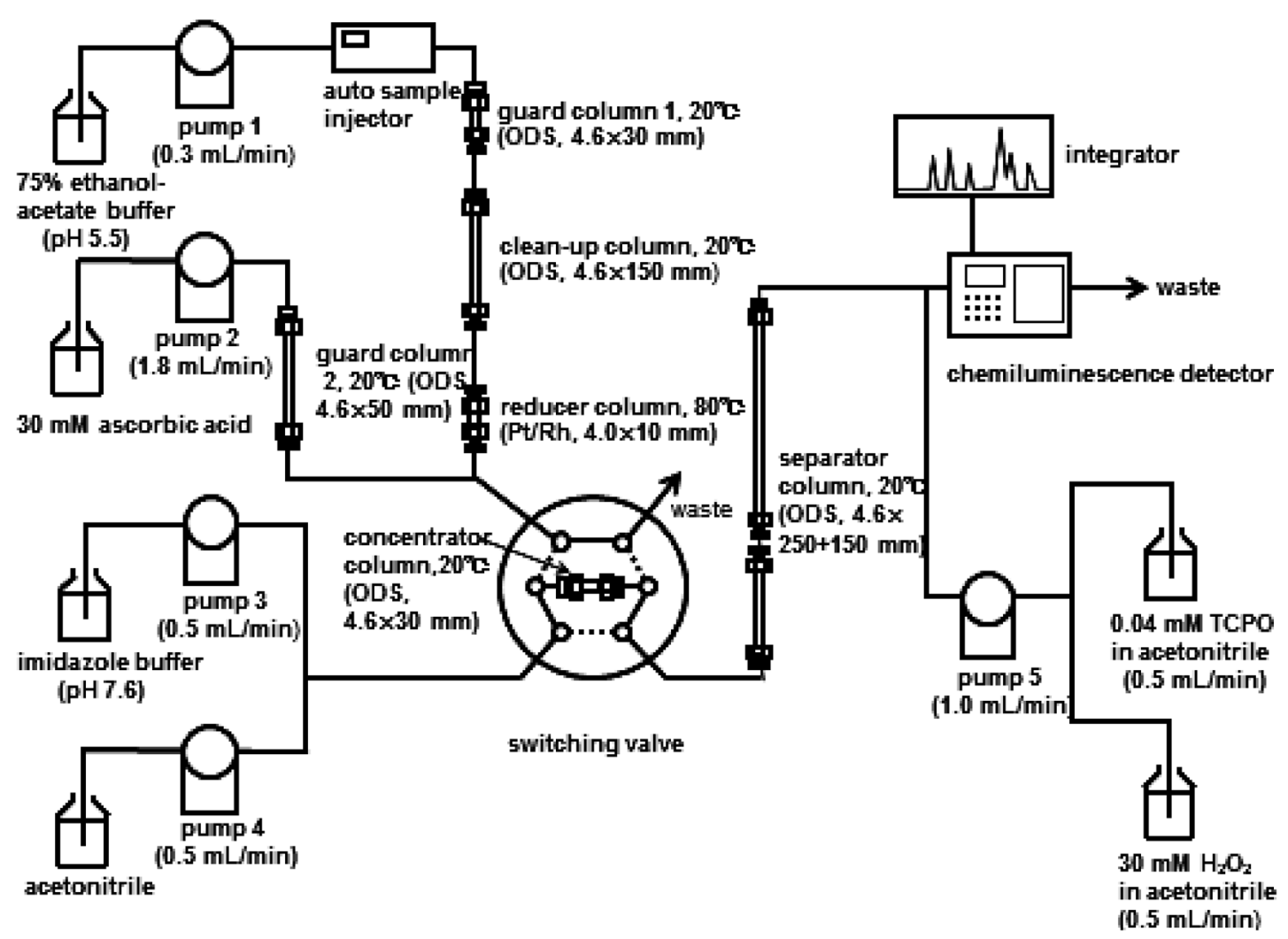

Fig. 1. Schematic Diagram of NPAH Analysis

Table 2. Recovery and Repeatability of Soluble NPAHs

\begin{tabular}{|c|c|c|c|c|c|}
\hline NPAH & Non-spiked ${ }^{a)}$ & Spiked $^{a}$ & $\begin{array}{l}\text { Deter- } \\
\left.\text { mined }^{a}\right)\end{array}$ & $\begin{array}{l}\text { Recovery (\%) } \\
\text { mean } \pm \text { R.S.D. }\end{array}$ & $\begin{array}{c}\text { Repeatability } \\
\text { R.S.D. (\%) }\end{array}$ \\
\hline 9-NA & 0.82 & 6.20 & $6.34 \pm 1.2$ & $89 \pm 5.9$ & 4.2 \\
\hline $1-\mathrm{NP}$ & 0.13 & 0.61 & $0.62 \pm 0.04$ & $80 \pm 5.1$ & 5.2 \\
\hline 6-NC & N.Q. & 1.79 & $1.85 \pm 0.11$ & $103 \pm 6.1$ & 6.0 \\
\hline 7-NBaA & 0.06 & 0.77 & $0.61 \pm 0.02$ & $71 \pm 5.6$ & 5.4 \\
\hline 6-NBaP & 0.14 & 1.73 & $1.62 \pm 0.05$ & $86 \pm 2.3$ & 6.8 \\
\hline
\end{tabular}

a) Concentrations are in nmol/L $(n=5)$. N.Q. means "not quantified" because lower than LOQ.

The extraction method using $\mathrm{C} 18$ disk is not time consuming and uses little solvent. The use of less solvent is not only cheaper, but also more environment-friendly due to the reduced amounts of waste. By using a few steps in the procedure, the total amount of time used in extracting NPAHs from each $\mathrm{C} 18$ disk was $40 \mathrm{~min}$. The least amount of river water sample used was $1.5 \mathrm{~L}$ and several NPAHs could be detected even at trace levels.

Performance of the Proposed Method In order to assess the practical applicability of the proposed extraction methods for soluble and particulate phase coupled to the analytical system, performance parameters like linearity, limits of detection, limits of quantification and precision were measured under optimum analytical conditions. Calibration curves for each NPAH were calculated using 8 spiking levels in the concentration range shown in Table 4. Correlation coefficients $\left(r^{2}\right)$ ranged between 0.9954 and 0.9998 . Recoveries ranged from 71 to $103 \%$ for soluble phase NPAHs (Table 2) with relative standard deviation (R.S.D.) of between $2.3 \%$ and $6.1 \%$ while for particulate phase NPAHs (Table 3), the recovery ranged
Table 3. Recovery and Repeatability of Particulate NPAHs

\begin{tabular}{|c|c|c|c|c|c|}
\hline NPAH & Non-spiked ${ }^{a}$ & Spiked $^{a)}$ & $\begin{array}{l}\text { Deter- } \\
\text { mined }^{a)}\end{array}$ & $\begin{array}{l}\text { Recovery (\%) } \\
\text { mean } \pm \text { R.S.D. }\end{array}$ & $\begin{array}{c}\text { Repeatability } \\
\text { R.S.D. (\%) }\end{array}$ \\
\hline 9NA & 0.06 & 0.62 & $0.53 \pm 0.09$ & $76 \pm 6.1$ & 2.5 \\
\hline $1-\mathrm{NP}$ & 0.13 & 0.61 & $0.58 \pm 0.01$ & $74 \pm 4.8$ & 2.2 \\
\hline 6-NC & N.Q. & 1.79 & $1.86 \pm 0.04$ & $103 \pm 2.3$ & 2.8 \\
\hline 7-NBaA & 0.05 & 0.77 & $0.59 \pm 0.02$ & $70 \pm 2.6$ & 2.5 \\
\hline 6-NBaP & 0.04 & 0.26 & $0.25 \pm 0.01$ & $81 \pm 3.2$ & 2.3 \\
\hline
\end{tabular}

a) Concentrations are in nmol/L $(n=5)$. N.Q. means "not quantified" because lower than LOQ.

from 70 to $103 \%$ with R.S.D. ranging between $2.3 \%$ and $6.1 \%$.

Repeatability, expressed as R.S.D. was between $4.2 \%$ and $6.8 \%$ for soluble phase NPAHs $(n=5)$ and was between $2.2 \%$ and $2.8 \%$ for particulate phase NPAHs $(n=5)$. Limits of detection calculated from standard deviations obtained from spike tests ranged from $0.013 \mathrm{nmol} / \mathrm{L}(7-\mathrm{NBaA})$ to $0.15 \mathrm{nmol} / \mathrm{L}$ (6-NC) for soluble NPAHs, and from 0.01 (6-NBaP) to 0.13 (6-NC) for particulate NPAHs when $100 \mu \mathrm{L}$ of sample solution was injected for analysis. 6-NC had higher LOD than other NPAHs due to its low sensitivity.

The LODs determined by the proposed method were much lower than those determined using solid phase microextraction with GC/MS analysis. The LOD of 1-NP was $0.059 \mu \mathrm{g} /$ $\mathrm{L}^{17)}$ which is about 7 times and 7.5 times higher (for soluble and particulate NPAHs, respectively) than the LODs of 1-NP determined in this report. The LODs of 9-NA and 1-NP using electrochemical methods like DPP, DPV and AdSV were also reported. The LODs of $1-\mathrm{NP}$ were $250 \mathrm{nmol} / \mathrm{L}$ using DPP, $60 \mathrm{nmol} / \mathrm{L}$ using DPV and $0.9 \mathrm{nmol} / \mathrm{L}$ using AdSV. For 9-NA, LOD using DPP was $200 \mathrm{nmol} / \mathrm{L}$, for DPV it was $100 \mathrm{nmol} / \mathrm{L}$ 
Table 4. Linearity, Limits of Detection and Limits of Quantification of the Proposed Method

\begin{tabular}{|c|c|c|c|c|c|c|}
\hline \multirow{2}{*}{ NPAH } & \multirow{2}{*}{ Linearity $\left(r^{2}\right)$} & \multirow{2}{*}{$\begin{array}{l}\text { Concentration range } \\
(\mathrm{nmol} / \mathrm{L})\end{array}$} & \multicolumn{2}{|c|}{ Soluble NPAHs } & \multicolumn{2}{|c|}{ Particulate NPAHs } \\
\hline & & & $\mathrm{LOD}^{a}$ & $\mathrm{LOQ}^{b)}$ & $\mathrm{LOD}^{a}$ & $\mathrm{LOQ}^{b)}$ \\
\hline 9-NA & 0.9995 & $0.02-4$ & 0.092 & 0.31 & 0.015 & 0.05 \\
\hline $1-\mathrm{NP}$ & 0.9998 & $0.04-4$ & 0.035 & 0.117 & 0.032 & 0.11 \\
\hline 6-NC & 0.9954 & $0.08-4$ & 0.15 & 0.504 & 0.13 & 0.42 \\
\hline 7-NBaA & 0.9998 & $0.04-4$ & 0.013 & 0.043 & 0.014 & 0.047 \\
\hline 6-NBaP & 0.9997 & $0.04-4$ & 0.041 & 0.14 & 0.01 & 0.033 \\
\hline
\end{tabular}

S.D. $=$ Standard deviation. $a$ ) LOD is in $\mathrm{nmol} / \mathrm{L}($ S.D. $\times 3) . b)$ LOQ is in $\mathrm{nmol} / \mathrm{L}($ S.D. $\times 10)$
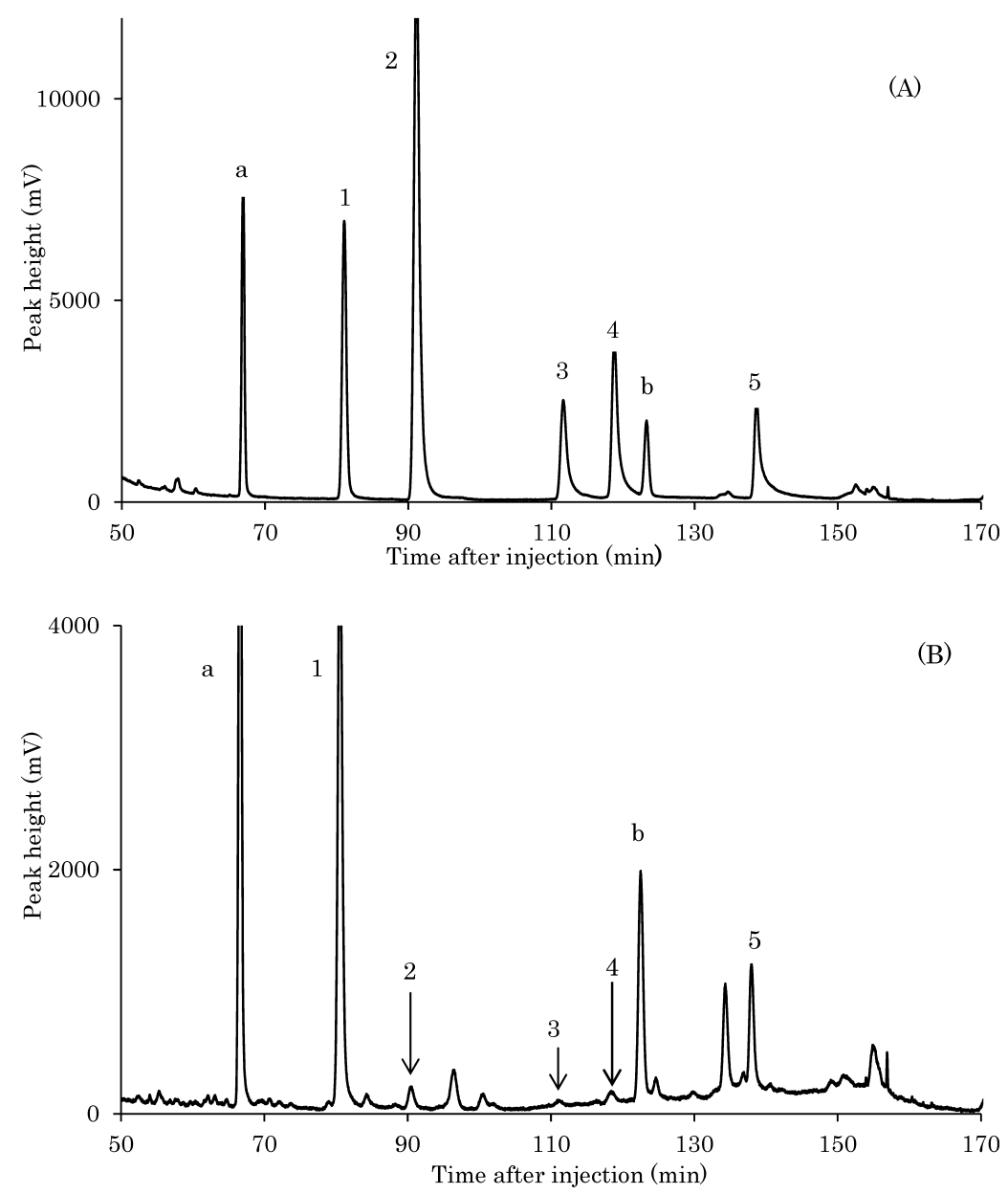

Fig. 2. Chromatograms of Standard NPAH Solution and River Water Sample

(A) Standard NPAH solution: (a) FNF, 1000 (b) system peak (1) 9-NA, 4 (2) 1-NP, 20 (3) 6-NC, 25 (4) 7-NBaA, 5 (5) 6-NBaP, 1 (nmol/L). (B) Asano river sample (1.5 L): (a) FNF, (b) system peak (1) 9-NA, 2.16 (2) 1-NP, 0.2 (3) 6-NC, below LOQ (4) 7-NBaA, 0.08 (5) 6-NBaP, 0.17 (nmol/L).

and for AdSV it was $2 \mathrm{nmol} / \mathrm{L}$. Although AdSV showed low LOD compared to the other two electrochemical methods, the method couldn't be used practically due to the passivation of the electrode surface by impurities when more complicated matrices were used. DPV was therefore used to determine NPAHs spiked into river water. ${ }^{18)}$ These LODs, even when AdSV is used, are still about 26 times and 28 times higher (for soluble and particulate NPAHs, respectively) than the LODs of 1-NP determined in this report. For 9-NA, LODs determined using ADSv are about 22 times and 133 times higher (for soluble and particulate NPAHs, respectively) than the LODs of 9-NA determined in this report.

Application to Environmental Samples The proposed method was used to successfully determine NPAHs in $1.5 \mathrm{~L}$ of real river water samples. All peaks of the five NPAHs were observed in the river water sample (Fig. 2B) at the same retention times of standard NPAHs including FNF as an internal standard (Fig. 2A). The time shown on the horizontal axis of the chromatogram indicates total time after injection of samples. The separation of NPAHs on the separator columns started at $42 \mathrm{~min}$ after the injection. Concentration of 9-NA was highest $(2.16 \mathrm{nmol} / \mathrm{L})$, followed by $1-\mathrm{NP}(0.2 \mathrm{nmol} / \mathrm{L})$, $6-\mathrm{NBaP}(0.17 \mathrm{nmol} / \mathrm{L})$ and the concentration of $7-\mathrm{NBaA}$ was lowest $(0.08 \mathrm{nmol} / \mathrm{L})$. $6-\mathrm{NC}$ was also detected but was below the LOQ in this study. This can be explained by the low sensitivity of 6-NC, and also the low concentration of 6-NC in this river water. The quantitative recoveries of the five NPAHs spiked into river water samples were obtained by increasing 
the sample volume up to $10 \mathrm{~L}$, suggesting that 6 -NC in the river water sample in Fig. $2 \mathrm{~B}$ could be quantified by increasing the sample volume.

\section{Conclusion}

This report has developed a new determination method for trace levels of NPAHs in environmental water samples (river water). The proposed method consists of the separation of particulate and soluble phases, concentration of the soluble phase NPAHs by using a $\mathrm{C} 18$ disk and an online concentration/ reduction/separation and chemiluminescence detection HPLC system. The proposed method determined ultra-trace levels of selected NPAHs in river water samples. The method is useful because of the small amount of water needed, and the use of solvent is reduced, making it cheaper and more environment friendly due to less waste produced. More NPAHs can be quantified by increasing the volume of water used.

Acknowledgments This work is supported in part by Grants-in-Aid for Scientific Research (Nos. 21256001 and 21390034) from the Ministry of Education, Culture, Sports, Science and Technology of Japan and the Environmental Research and Technology Development Fund (B-0905) from the Ministry of Environment, Japan. This work was supported in part by a scholarship award to the author from the College Women's Association of Japan. The author acknowledges Dr. Hossam Nassar of the National Research Center, El Buhouth St., Dokki, Cairo, Egypt, for his invaluable advice and useful comments.

\section{References}

1) Khalili N. R., Scheff P. A., Holsen T. M., Atmos. Environ., 29, 533-542 (1995).

2) Blumer M., "Polycyclic aromatic hydrocarbons in nature.": 〈http:// www.osti.gov/energycitations/product.biblio.jsp?osti_id=5640085, cited 24 June, 2013.

3) Arey J., Zielinska B., Atkinson R., Winer A. M., Ramdahl T., Pitts J. N. Jr., Atmos. Environ., 20, 2339-2345 (1986).

4) Ishii S., Hisamatsu Y., Inazu K., Kadoi M., Aika K., Environ. Sci.
Technol., 34, 1893-1899 (2000).

5) Yaffe D., Cohen Y., Arey J., Grosovsky A. J., Risk Anal., 21, 275 294 (2001).

6) "Agents Classified by the IARC Monographs," Volumes 1-105, 2012 http://monographs.iarc.fr/ENG/Classification/Classifications AlphaOrder.pdf>

7) Ohgaki H., Negishi C., Wakabayashi K., Kusama K., Sato S., Sugimura T., Carcinogenesis, 5, 583-585 (1984).

8) Tang N., Hattori T., Taga R., Igarashi K., Yang X., Tamura K., Kakimoto H., Mishukov V. F., Toriba A., Kizu R., Hayakawa K., Atmos. Environ., 39, 5817-5826 (2005).

9) Feilberg A., Poulsen M. W., Nielsen T., Skov H., Atmos. Environ., 35, 353-366 (2001).

10) Araki Y., Tang N., Ohno M., Kameda T., Toriba A., Hayakawa K., J. Health Sci., 55, 77-85 (2009).

11) Zielinska B., Samy S., Anal. Bioanal. Chem., 386, 883-890 (2006).

12) Luque-García J. L., Luque de Castro M. D., Analyst, 128, 980-985 (2003).

13) Priego-Capote F., Luque-Garcia J. L., Luque de Castro M. D., J. Chromatogr. A, 994, 159-167 (2003).

14) Li Y., Yoshida S., Chondo Y., Nassar H., Tang N., Araki Y., Toriba A., Kameda T., Hayakawa K., Chem. Pharm. Bull., 60, 531-535 (2012).

15) Zhou J. L., Maskaoui K., Environ. Pollut., 121, 269-281 (2003).

16) Hayakawa K., Biomed. Chromatogr., 14, 397-405 (2000).

17) Mekiki D., Kalogerakis N., Psillakis E., Chromatographia, 63, 85-89 (2006).

18) Barek J., Pumera M., Muck A., Kadeřábková M., Zima J., Anal. Chim. Acta, 393, 141-146 (1999).

19) Martinez E., Gros M., Lacorte S., Barceló D., J. Chromatogr. A, 1047, 181-188, (2004).

20) Hayakawa K., Kitamura R., Butoh M., Imaizumi N., Miyazaki M., Anal. Sci., 7, 573-577 (1991).

21) Hayakawa K., Murahashi T., Butoh M., Miyazaki M., Environ. Sci. Technol., 29, 928-932 (1995).

22) Tang N., Taga R., Hattori T., Toriba A., Kizu R., Hayakawa K., "Proceedings of the 13th International Symposium, Bioluminescence \& Chemiluminescence, Progress and Perspectives," ed. by Tsuji A., Matsumoto M., Maeda M., Kricka L. J., Stanley P. E., World Scientific Publishing Co., Pte. Ltd., Singapore, 2005, pp. 441-444.

23) Murahashi T., Ito M., Kizu R., Hayakawa K., Water Res., 35, 33673372 (2001). 